4-2010

\title{
Denial in Alcohol and Other Drug Use Disorders: A Critique of Theory.
}

Patricia A. Stoddard Dare

Cleveland State University, p.stoddarddare@csuohio.edu

LeaAnne DeRigne

Florida Atlantic University, Iderigne@fau.edu

Follow this and additional works at: https://engagedscholarship.csuohio.edu/clsowo_facpub

Part of the Social Work Commons, and the Substance Abuse and Addiction Commons How does access to this work benefit you? Let us know!

\section{Publisher's Statement}

(c) Informa Healthcare

\section{Recommended Citation}

Stoddard Dare, Patricia A. and DeRigne, LeaAnne, "Denial in Alcohol and Other Drug Use Disorders: A Critique of Theory." (2010). Social Work Faculty Publications. 19.

https://engagedscholarship.csuohio.edu/clsowo_facpub/19

This Article is brought to you for free and open access by the School of Social Work at EngagedScholarship@CSU. It has been accepted for inclusion in Social Work Faculty Publications by an authorized administrator of EngagedScholarship@CSU. For more information, please contact library.es@csuohio.edu. 


\title{
Denial in alcohol and other drug use disorders: A critique of theory
}

\author{
PATRICIA ANN STODDARD DARE ${ }^{1} \&$ LEAANNE DERIGNE ${ }^{2}$
}

${ }^{1}$ Social Work Department, Cleveland State University, 2121 Euclid Avenue, CB 320

Cleveland, $\mathrm{OH}$ 44115, USA and ${ }^{2}$ Assistant Professor, Florida Atlantic University, College of

Architecture, Urban Affairs and Public Administration School of Social Work, 777 Glades Road, SO

284, Boca Raton, ILL 33341, USA

\begin{abstract}
Despite the centrality of the construct in the field of alcohol and other drug (AOD) addiction, denial remains poorly conceptualized. One reason for this narrow conceptualization is the recent unilateral devotion to the Transtheoretical Model (TTM). In an effort to demonstrate denial's theoretical complexity, the TTM and five additional intuitively appealing theories of denial will be summarized. The strengths and weaknesses of each theory and possible treatment implications based on each theory will also be presented. The article concludes with a recommendation for future research to evaluate multiple theories of denial using consistent and rigorous research methodology in order to develop a comprehensive theory of denial. This will promote evolution of the deductive research process, and eventually lead to the development of empirically generated interventions which address the complex nature and etiology of denial.
\end{abstract}

Keywords: Denial, substance abuse, alcohol and other drug dependence, theory, addiction, stagts of thunge

Despite efforts for over 40 years to redefine, normalize, work with, and dertop intericution strategies, denial is the most frustrating aspect of treating the alcoholic. This is dice, in large meastric, to a failure to take into account the complexity of the construct (Weinstein et al. 1009).

\section{Background}

In the year 2006, 25 million persons worldwide suffered from drug addiction or problem drug use. This is the equivalent of $0.6 \%$ of the adult population between the ages of $15-04$ (LN

Correspondence: P.A.S. Dare, Social Work Department, Cleveland Stute University, 2121 Fuclid Avenue, C.B 320, Cleveland, OH 44115, USA. Tel.: (216) 687-4568. Fax: (561) 297-2866. F-mail: p.stoddarddare (a csuohio.edu

ISSN 1606-6359 print ISSN 1476-7392 online C 2010 Informa Healthcare Lrd.

DOI: $10.3109 / 16066350902770441$ 
2006). Nearly $5 \%$ of adults worldwide have used illicit drugs within the last year and about half of those reported use within the last month. Cannabis is the most prevalently abused illicit drug followed by cocaine and opiates. Tobacco (classified as a licit drug), is used by $28 \%$ of the world's adult population (UN 2006). Two billion people consumed alcohol in the year 2004 with over 76 million classified as having diagnosable alcohol use disorders (WHO 2004). Poland reports the highest rate of alcohol dependence $(12.2 \%$ of the adult population) followed by Brazil (11.2\%). Alcohol use can be attributed to 1.8 million deaths worldwide (over a third of which are unintentional injuries) (WHO 2004).

In the United States over 22 million people in the year 2005 suffered from substance abuse or dependence as defined by the DSM-IV. This translates into $9.1 \%$ of the US population over the age of 12 . The majority of these people abused alcohol (15.4 million) while over 3.3 million abused both alcohol and illicit drugs and another 3.6 million were dependent on or abused only illicit drugs. Nearly 4 million people (of the 23.2 million SAMHSA reports need treatment) received treatment for alcohol or drug use in the same year which means that almost 20 million people did not receive needed treatment. Of these 20 million people only 1.2 million reported that they felt they needed treatment (SAMHSA 2006). Many of these people may experience denial about their need for treatment.

Denial is a concept central to the field of alcohol and other drug (AOD) addiction. Indeed, the presence of denial is even included in the definition of alcoholism (Morse and Flavin 1992), and empirical evidence demonstrates that denial is the number one reason cited by alcoholics for not seeking treatment (Wing 1995; Grant 1997; Pal et al. 2003; To 2006). Despite the centrality of denial, it remains a poorly conceptualized construct. One result of this poor conceptualization is that empirically investigated interventions to address denial have been sparse. This is troubling because research suggests that practitioners feel unequipped to effectively intervene with AOD abusers who exhibit denial (Taylor and Kroll 2004; Forrester and Harwin 2006). Current clinical approaches to denial vary widely depending on which theory of denial is embraced. This article will present and discuss six theories of denial regarding AOD addictions that currently exist. The suggested clinical response to denial based on each theory will also be presented.

Broadly, the purpose of this article is to make steps towards reducing the negative effects of substance abuse disorders. Specifically, the purpose of this article is to: (1) call attention to the theoretical complexity of the construct denial, (2) demonstrate that the clinical response to denial varies depending on the theoretical perspective embraced, (3) organize the literature pertaining to etiological theories of denial and corresponding interventions, (4) provide a reference tool for counsellors and others who work with substance abusers who exhibit denial and (5) demonstrate the need for future research that develops and evaluates a comprehensive theory of denial. Acknowledging the complexity of denial sheds light on the importance of utilizing consistent and rigorous research methodology to evaluate multiple theories of denial. This will allow empirically generated interventions, which are informed by multiple theories of denial, to be created.

\section{Theories of denial}

Theorists from diverse fields of study have posited theories of denial in an effort to describe the role of denial in AOD disorders. The result is a collection of implicit and explicit theories that help elucidate the nature, etiology and possible treatment implications of denial. A unifying theory of denial, which integrates constructs from each of these theories, does not currently 
exist. Although this is not an exhaustive list of theories on denial, the following theories were selected because they are widely embraced popular or professional conceptualizations and they represent the diversity within theoretical conceptions of denial related to AOD abuse and dependence. The theories of denial that will be reviewed include the: (1) moral defect, (2) interactional, (3) mental impairment, (4) psychodynamic, (5) phenomenological and (6) stages of change models. A summary of the theories, including their strengths and weaknesses and possible clinical response, are presented in Table I (see attached).

\section{Moral defect model of denial}

This model of denial is rarely overtly expressed in the theoretical and empirical literature, but is an often-embraced popular and professional conceptualization of denial incorporating

Table I. Summary of Theories

\begin{tabular}{|c|c|c|c|c|}
\hline Theory & Attributes & Intervention & Strengths & Weaknesses \\
\hline Moral Defect & $\begin{array}{l}\text { - Lying due to } \\
\text { character defect }\end{array}$ & $\begin{array}{l}\text { - Moral } \\
\text { conversion }\end{array}$ & $\begin{array}{l}\text { - Consistent with } \\
\text { 12-step program }\end{array}$ & - Deficit-focused \\
\hline Interactional & $\begin{array}{l}\text { - Iatrogenic } \\
\text { consequence of } \\
\text { aggressive } \\
\text { confrontation }\end{array}$ & $\begin{array}{l}\text { - Motivational } \\
\text { Interviewing }\end{array}$ & $\begin{array}{l}\text { - Empirically } \\
\text { testable } \\
\text { - Practical } \\
\text { application }\end{array}$ & $\begin{array}{l}\text { - Perpetuates } \\
\text { external } \\
\text { attribution of } \\
\text { AOD problems }\end{array}$ \\
\hline $\begin{array}{l}\text { Mental } \\
\text { Impairment }\end{array}$ & $\begin{array}{l}\text { - Neuro-cognitive } \\
\text { impairment }\end{array}$ & $\begin{array}{l}\text { - Behavioral } \\
\text { interventions, } \\
\text { explaining } \\
\text { information } \\
\text { clearly in } \\
\text { small doses }\end{array}$ & $\begin{array}{l}\text { - Empirically } \\
\text { testable } \\
\text { - Practical } \\
\text { application }\end{array}$ & $\begin{array}{c}\text { Does not apply } \\
\text { to all cases }\end{array}$ \\
\hline Psychodynamic & $\begin{array}{l}\text { - Classic defense } \\
\text { mechanism }\end{array}$ & $\begin{array}{l}\text { - Psychoanalytic } \\
\text { treatment }\end{array}$ & $\begin{array}{l}\text { - Lends itself to } \\
\text { therapeutic } \\
\text { intervention }\end{array}$ & $\begin{array}{l}\text { - Constructs not } \\
\text { empirically } \\
\text { verifiable }\end{array}$ \\
\hline $\begin{array}{l}\text { Phenomeno- } \\
\text { logical }\end{array}$ & $\begin{array}{l}\text { Epistemological } \\
\text { quandary }\end{array}$ & - Education & $\begin{array}{l}\text { - Non-judgmental } \\
\text { - Ecological } \\
\text { approach } \\
\text { - Potential for } \\
\text { practical } \\
\text { applicability }\end{array}$ & $\begin{array}{l}\text { - Disregards } \\
\text { mental impairment, } \\
\text { psychodymic, and } \\
\text { biopsychological } \\
\text { explanations } \\
\text { - Limited to denial } \\
\text { of the label } \\
\text { addict or } \\
\text { alcoholic }\end{array}$ \\
\hline $\begin{array}{r}\text { Stages of } \\
\text { Change }\end{array}$ & $\begin{array}{l}\text { Precontemplators } \\
\text { are reluctant, } \\
\text { rebellious, } \\
\text { resigned, } \\
\text { rationalizing, } \\
\text { or reveling }\end{array}$ & $\begin{array}{l}\text { - Motivational } \\
\text { Enhancement } \\
\text { Therapy }\end{array}$ & $\begin{array}{l}\text { - Suggests denial } \\
\text { changes } \\
\text { over time } \\
\text { - Consistent with } \\
\text { some other } \\
\text { conceptualize- } \\
\text { tions of denial } \\
\text { - Less pejorative }\end{array}$ & $\begin{array}{l}\text { - Difficult to gain } \\
\text { an in-depth } \\
\text { understanding of } \\
\text { denial apart from } \\
\text { the other stages of } \\
\text { change } \\
\text { - Stages of change } \\
\text { may not be } \\
\text { mutually } \\
\text { exclusive } \\
\text { - Stage assessments } \\
\text { are arbitrary and } \\
\text { may lack validity }\end{array}$ \\
\hline
\end{tabular}


notions of character weakness and deception (Doweiko 2009; Stoltzfus 2006). According to this theory, denial is little more than a fancy term for lying (Krestan and Bepko 1993). Adherents of this theory believe that persons with AOD use disorders possess a moral defect (Stoltzfus 2006) which not only causes them to continue drinking or using drugs, but also to pathologically lie to themselves and/or others about their AOD use and its consequences (Kerns 1986). Denial thus reflects intentional deception which may only occur in certain circumstances or with certain people.

Opponents of the moral defect model of denial embrace a disease model of alcoholism (Jellinek 1960; Becker 1978; Wechsler and Rohman 1982; Sullivan and Hale 1987) and maintain that alcoholism is a disease that affects an individual's control over drinking. They believe that the disease of alcoholism, not the individual alcoholic, is responsible for lying behaviour. Insinuating that alcoholism and its byproducts are the alcoholic's fault is essentially blaming the victim. Indeed, they believe AOD dependency is a disease just like any other and denial is a cardinal symptom of that disease. To insinuate that denial is the result of a moral defect would be equivalent to saying that symptoms of any other diseases, such as pain from cancer, is also due to a moral defect (Hall 1993). In addition to this ideological objection to the moral defect model, some observers simply maintain that it runs contrary to their profession's strengths-based foundation (Siegal et al. 1995, 1996).

In terms of theory application, an appropriate intervention to overcome denial due to a moral defect would be to promote a moral conversion to help clients rise above their character defects (Khantzian 1999). An anomaly of the 12-step program of Alcoholics Anonymous is that, although it promotes the disease model of addiction, it also implicitly endorses the moral model by insisting that a frank look at one's own behaviour is a necessary prerequisite for recovery (Alcoholics Anonymous World Services 1956). The idea that a person needs to look to a higher power, conduct a searching moral inventory and ask for forgiveness from others for their alcohol-related trespasses is a reflection of this belief. Little attention has explicitly been given to this model of denial in the professional literature in recent decades, but it clearly is a widely embraced conceptualization of denial.

\section{Interactional model of denial}

According to the interactional model, denial is a predictable outcome of inappropriate aggressive confrontation by another person, often a family member or helping professional (Miller and Rollnick 2002). Reactance occurs when an individual feels like his or her freedom or autonomy is threatened (Brehm 1976). In this case, as a result of aggressive confrontation, substance abusers may feel that their freedom to continue using their preferred substance is threatened. Denial; therefore, is an iatrogenic consequence to aggressive confrontation.

Strengths of this theory are that it lends itself to empirical testing and has the potential for clinical applicability. An important limitation of this theory is that it redirects attention away from the AOD abuser and may perpetuate external attribution for AOD problems.

One proposed solution to denial due to aggressive confrontation is to utilize motivational interviewing (Miller and Rollnick 2002) which is a non-confrontational, supportive intervention in which individuals with AOD disorders are gently supported through the process of resolving their ambivalence about substance abuse. The goal of motivational interviewing is to help substance abusers weigh the pros and cons of their continued substance abuse and to help them recognize their options. Individuals are approached in 
a non-judgemental, objective manner. This is a process that takes time and patience on the part of the helper.

Studies have evaluated the level of resistance/denial and drinking behaviour exhibited by clients after being exposed to either confrontational or motivational interviewing techniques (Miller and Sovereign 1989). Miller and Sovereign (1989) found that post treatment resistance and subsequent drinking were higher among individuals who were exposed to a confrontational intervention.

Conversely, other studies have indicated that 'attack therapy' is an effective intervention to resolve denial (Kennard 1983). A closer review of the literature shows the mixed impact of aggressive confrontation on drinking behaviour depending on how emotional the exchange is, the clinical context, the recipients' appraisal of the confronters' motivations, the perceived accuracy of the charge, client characteristics and the relationship between the confronter and confrontee (Miller et al. 1993; Polcin and Weisner 1999; Polcin 2003). Further research is needed to investigate these contradictions.

\section{Mental impairment model of denial}

Several theorists have argued that some individuals exhibit denial of AOD disorders and related problems due to neurocognitive impairment (Miller and Barasch 1985; Duffy 1995; Fals-Stewart et al. 1995; Rinn et al. 2002). Two different kinds of mental impairment have been identified: short-term impairment caused by current intoxication and acute withdrawal symptomatology (e.g. hangover) (Duffy 1995; Zinn et al. 2004), and long-term impairment caused by neurotoxicity secondary to prolonged substance abuse (Charness 1993; Duffy 1995; Edwards et al. 1973; Grant 1997; F. Miller and Barasch 1985; Wiseman et al. 1996; Moselhy et al. 2001). Although each type of abused substance impacts the brain in a unique way, and biological differences such as gender may impact the severity of the damage to cognitive functioning (Nixon 1998; van der Walde et al. 2002), the effects of alcohol demonstrate how neurotoxicity can present as denial.

Clinical research has shown that alcoholic dementia impacts the frontal lobes and right hemisphere of the brain (Jones 1971; Miglioli et al. 1979; Lyvers 2000). These areas are responsible for monitoring an individual's interpersonal world (Duffy and Campbell 1994). Therefore, 'anosagnosia', or 'an inability to comprehend the negative implications of one's predicament' (Duffy 1995 p. 259) may occur. Although a complicated physiological sequence of events takes place due to alcohol-related neurotoxicity, the behaviour and emotions expressed by an alcoholic are interpreted as denial (Duffy 1995).

One strength of this theory is its potential for practical utility. Psychotherapeutic or confrontational techniques to reduce a client's denial might be counterproductive if it were shown that denial is largely a function of neurologically-based cognitive limitations. Indeed, based on this theory, an appropriate treatment intervention would be to present information to clients in small increments, rather than presenting large amounts of information from multiple sources to 'break through denial'. This theory has been empirically evaluated (Rinn et al. 2002). Although the findings support the theory, the methodology has been criticized (Strauss 2002): the indicator used to measure denial was weak.

\section{Psychodynamic model of denial}

One of the most widely accepted theories of denial is the classic psychodynamic formulation (Freud 1961; Royce 1981; Dorpat 1994; Nace 1987; Krestan and Bepko 1993; Litowitz 
1998; Miceli and Castelfranchi 1998; Shaffer and Simoneau 2001; Johnson 2003). Evolved directly from the work of Sigmund Freud, this theory posits that individuals with substance use disorders utilize denial, one of a set of classic defence mechanisms, in order to prevent psychically threatening thoughts and feelings from entering consciousness.

Freud identified five important properties of all defence mechanisms, emphasizing that they are: (1) a way of managing instinct and affect (i.e. sexual and aggressive urges), (2) unconscious, (3) distinct from each other, (4) reversible and (5) potentially adaptive and pathological (cited in Vaillant 1988). Furthermore, defence mechanisms such as denial help to moderate extreme emotional reactions to changes in one's life by providing a person with time to integrate negative information about oneself. According to this theoretical perspective, short-term reliance on defence mechanisms might be healthy for self-esteem maintenance; however, if they are used too often or for too long, their use can become maladaptive. Proponents of this perspective assert that denial is a normal grief response (Johnson 2004) which can be adaptive as well as pathological (Bean 1981; Krestan and Bepko 1993).

Valliant (1988) implicitly admitted to the empirical shortcomings of defence mechanisms when he stated that they 'do not reflect actual neuronal assemblies but rather serve as metaphors to describe higher integrated processes of the central nervous system' (p. 204). Indeed, as with all of the classic defence mechanisms, the psychodynamic theory of denial does not lend itself to empirical testing and its existence cannot be accurately measured.

Despite these shortcomings, this model of denial has strengths. First, it implies that denial can be overcome through a classic psychoanalytic treatment approach such as free association, dream analysis or therapeutic intervention aimed at reducing the cognitive dissonance or extreme emotional reaction that prevents the conscious integration of the information the individual is denying (Forrest 1985). Since individuals utilize denial to protect themselves from psychic pain, the substance abuser needs to be given new tools for coping with that pain. Clinicians help decrease the pain by acknowledging it and offering hope.

\section{Phenomenological model of denial}

Another theory that has been forwarded to explain denial uses a phenomenological approach. Phenomenology by definition refers to the typological classification of phenomena. In this case, the classification of behaviours that constitute AOD disorders is in question. Wallace (1986) argues that rather than reflecting an unconscious process, denial is more properly understood as an 'epistemological quandary' faced by the problem drinker (Wallace 1986). This theory posits a view of denial that is sympathetic to alcoholics' difficulty in determining whether their personal behaviours are consistent with those seen in AOD use disorders. Four reasons for this quandary are postulated. First, AOD use disorders are formulaic, wherein no one symptom indicates a diagnosis of alcohol or drug dependence with certainty, and the significance of any one symptom is a function of the number and nature of other symptoms present. Second, the individual with an AOD use disorder did not always get drunk or high when previously using those substances, particularly early in the course of the substance using career. Third, negative consequences did and (do) not inevitably follow AOD use (Schuckit et al. 1998). And finally, many positive memories likely remain regarding prior substance use (McMahon and Jones 1992). Therefore, Wallace suggests that persons with AOD use disorders may be understandably unsure whether or not their intermittent and individualized substance abuse patterns reflect 
dependence. Other variables not noted by Wallace that may complicate this epistemological quandary include: an individual's personal definition of alcoholism or drug abuse, the saliency of AOD-related problems, the number and type of AOD-related problems they have experienced, their attribution of AOD-related problems to alcohol or other drugs and their reference group. For example, an individual may drink 10 beers daily and think that his drinking is normal compared to his friends, most of whom drink 20 beers daily.

Strengths of this theory are that it is logical, empirically-testable and has potential for practical application. One weakness of this theory is that what is being denied seems to be narrowly limited to the label 'alcoholic' or 'addict'. Studies have been conducted that compare individuals that self-identify as 'alcoholics' with those who self-identify as 'non-alcoholics' (e.g. Skinner 1982). However, no studies to date have evaluated the specific variables discussed in Wallace's theory, or the label 'addict,' which may carry a different level of stigma than the label 'alcoholic'.

\section{Stages of change model of denial}

The stages of change theory, one component of the transtheoretical model (TTM), has enjoyed tremendous popularity. Unlike the other theories of denial reviewed in this article, this model does not focus solely on how or why denial occurs. Instead, the stages of change model, a meta-theory, explains the process individuals go through when becoming addicted to a substance (stages of change to addiction), and when deciding to change their substance use behaviour (stages of change to recovery) (Prochaska and DiClemente 1983, 1992; DiClemente 1991, 2003; DiClemente et al. 1991). Only one of the five stages of change, when describing the stages of change to recovery (not the stages of change to addiction), pertains to denial. Although the TTM is not an explanatory model of denial, it is included in this review because it has been so widely accepted among clinicians and researchers that alternative models have virtually been ignored for years (West 2005). As a result, the majority of social science research on denial in the last decade has focused on stages of change. Below, a brief overview of the stages of change model is presented, with particular attention focused on the 'Precontemplation' stage which is sometimes used interchangeably with the term denial.

According to this model, people with substance use disorders pass through five stages regarding their perceptions of their behaviour and their perceived need to curtail their substance use. These stages include (1) 'Precontemplation', (2) 'Contemplation', (3) 'Determination', (4) 'Action' and (5) 'Maintenance' (described in detail elsewhere, see DiClemente 2003). Individuals in the first stage of change, 'Precontemplation', are not considering the possibility of changing their substance using behaviour in the next 6 months. The second stage, 'Contemplation', is marked by ambivalence. In this stage individuals are willing to contemplate the possibility of change, but are not yet willing to make a decision about modifying their behaviour. In the third stage, 'Determination', individuals make a strong commitment to alter their behaviour. During this stage, a plan for change is devised. The next stage is the 'Action' stage. During this stage, individuals actively begin to change. The final stage of change is the 'Maintenance, Relapse and Recycling' Stage. During this stage, a new behaviour pattern is adhered to and the risk of reverting to the old behaviour becomes less pronounced. If relapses occur, the earlier stages are cycled through once again.

Descriptions of the 'Precontemplation' stage (DiClemente 2003) illustrate different factors which ostensibly contribute to denial. Indeed, individuals at this stage are either 
reluctant to change, resistant to change (i.e. rebellious), resigned to their inability to change, rationalize why they do not need to change or are too busy revelling in their addiction to consider change (DiClemente 2003). Those who are reluctant to change usually lack knowledge or motivation regarding their need to change. Those who are resistant to change do not like to be told what to do. They may have fear or insecurity about the possibility of changing their behaviour that presents itself as rebellion. Those who are resigned lack the sense of self-efficacy needed to change. They believe that it is no longer possible for them to get better. Those who rationalize why they do not need to change may acknowledge that substance abuse may be a serious problem for others, but they are convinced that this does not apply to them. Rationalizers express themselves through the presentation of facts rather than emotions. The final type of 'Precontemplator' is the one who is too busy revelling in their addictive behaviour to contemplate change. Negative consequences associated with their addiction are outweighed by the perceived benefits.

The stage of change theory has been critiqued and revised by many theorist and researchers. For example, Freeman and Dolan (2001) have expanded the theory to include 10 stages. Relevant to this discussion, according to their conceptualization, the 'Precontemplation' stage is replaced by three distinct stages. The first stage, 'Noncontemplation', describes individuals who do not overtly reject or deny change, they simply have not considered change. The second stage, 'Anticontemplation', describes individuals who actively avoid, oppose or resist change. The third stage, 'Precontemplation', is reconceptualized to describe an individual who begins contemplating the possibility of change. The Noncontemplation and Anticontemplation stages are particularly relevant to denial. In the Prochaska and DiClemente model Precontemplation is used to describe individuals who are not contemplating change for a variety of reasons. Freeman and Dolan's model (2001) distinguishes between those who are passively versus actively uninterested in change.

Various counseling interventions such as motivational enhancement therapy (MET) (Miller et al. 1992), substance abuse education, dramatic relief and environmental reevaluation are seen as appropriate strategies to be used with individuals in Prochaska and DiClemente's 'Precontemplation' stage (Prochaska and DiClemente 1992). Cognitive behavioural therapy has been introduced as an appropriate intervention for individuals in Freeman and Dolan's 'Noncontemplation' or 'Anticontemplation' stages (Dolan 2005). Although MET is the most widely embraced intervention to address Precontemplation, some research indicates that brief motivational interventions may not be comprehensive or intensive enough (DiClemente 2003).

One strength of this theory is that it does address the idea that denial changes over time. The temporally situated nature of denial should be considered in any comprehensive theory of denial. Another potential strength is the fact that this theory is consistent with some other conceptualizations of denial. For example, the rebellion explanation is consistent with the interactional theory and the resignation explanation coincides with other literature about denial and self-efficacy (Bandura 1977; Cardoso 1997). Finally, some believe using the term Precontemplation is less pejorative and more functional (DiClemente 2003) than the term denial.

One weakness of utilizing the TTM as an explanatory theory of denial is that the theory focuses broadly on the change process. As a result, a discussion of denial invariably becomes a discussion about all of the stages of change, foiling attempts to gain an in-depth understanding of denial apart from the other stages of change. Indeed, a co-developer of the TTM downplayed the complexity of denial by stating, 'the problem of denial is really nothing more than the conviction of addicted individuals that at the present moment it is not 
in their best interest to change' (DiClemente 2003 p. 113). The TTM captures the complexity of addictive behaviour change, but not the complexity of denial. Another criticism related to the TTM is that the relevance and structure of the model itself has been called into question (West 2005). For example, research suggests that the stages of change may not be mutually exclusive, and stage assessments are arbitrary and lack validity (Littell and Girvin 2002).

\section{Theories of denial summary}

This review elucidates prior theoretical work regarding denial and paints a picture of a diverse concept that intuitively appears to involve more than precontemplation due to reluctance, rebelliousness, resignation, rationalization or reveling. Indeed denial is a complex construct which has been characterized by dishonesty, interpersonal difficulties, brain injury, an ego defence mechanism, an absence of education or poor motivation.

\section{Implications}

\section{Research}

Although extensive, thoughtful work has been completed on the topic, research regarding denial in substance use disorders is in its infancy. As it is currently understood, measured and applied, denial primarily serves as an obstacle to researchers and practitioners. Indeed, haphazard and incomplete theoretical conceptualization of denial (and corresponding measurement of denial) has produced little guidance for individuals working to reduce the harmful effects of substance use disorders. Given the ubiquitous and disruptive nature of denial, the concept is clearly relevant to the field. It is imperative that we refine our inquiry in order to advance our knowledge and ability to effectively intervene.

Individually, no particular theory holds enough promise to exert a substantial influence on substance abuse treatment and prevention. However, collectively, these theories have tremendous potential to change the way that people understand denial and intervene with denial in substance abusers. It is quite possible that a combination of constructs from several of these theories most accurately represents what is truly driving denial.

This article calls for the development and evaluation of a comprehensive explanatory theory of denial utilizing constructs from many of these theories. Previous efforts have been made to evaluate some of these theories; however, a standard definition and measure of denial has not been utilized. It makes little sense to continue the current practice of defining and measuring denial differently among various studies. When denial is not measured consistently, it is impossible to generalize the findings from one empirical review of a theory to another. Before future studies are initiated, important measurement and definitional issues regarding denial need to be resolved. Specifically, a standard reliable and valid measure of denial should be consistently utilized to evaluate an integrated theoretical model.

Operational indicators should be utilized to measure morality, cognitive functioning, ego deficits (a proxy may need to be used), knowledge of the criterion of abuse and dependence, experience with aggressive confrontation, reluctance, rebelliousness, resignation, rationalization and revelling. The variable denial, should be measured at various points in time to evaluate the extent to which it fluctuates over time. Additionally, what is being denied 
should also be evaluated. For example, the phenomenological theory may explain denial of the label alcoholic, whereas the interactional model may predict denial of the consequences of AOD abuse on marriage. Each of these theories may, in fact, correctly characterize a particular element being denied.

\section{Clinical}

A clear clinical implication of this article is that it will give clinicians an historical review of the dominant theories on denial in order to increase the heuristic value of the construct. It will also serve as a unique reference tool that can assist them in making informed decisions about what treatment may work for a particular client. Intuitively, it makes sense that denial may stem from different sources for different individuals. Therefore, an intervention to address denial due to mental impairment may be different than an intervention to address denial due to revelling. A diagnostic assessment to evaluate denial and the underlying mechanisms which contribute to denial should be created to assist clinicians. A decision tree can then be used to determine an appropriate intervention based on the etiology of a client's denial.

\section{Conclusion}

Denial is the number one cited reason for failing to seek treatment among substance abusers, and most clinicians report that they do not know how to appropriately intervene with a client displaying denial. Intuitively appealing explanatory theories of denial and corresponding possible treatment implications exist. In part due to the enormous popularity of the TTM, to date, many other theories of denial remain untested. And, those that have been tested have not utilized consistent, rigorous research methods. Lack of consensus regarding the theoretical underpinnings of denial is reflected in the haphazard way that denial has been defined and measured in empirical studies and also limits the clinical utility of the construct. A comprehensive theoretical model which includes diverse conceptualizations of denial needs to be created and tested. Only then can empirically generated interventions to address denial be developed.

This article is one step in a series of necessary actions which collectively should increase the heuristic value of denial. Before further explicit and functional recommendations can be made regarding how to identify and reduce denial for clinical benefit, a series of steps must be taken. First, a broadly conceived nominal and operational definition of denial needs to be developed, accepted and utilized by various disciplines invested in understanding the substance abuse process such as medicine, psychology, nursing and social work. Second, a valid and reliable measurement instrument which captures etiological and descriptive features of denial should be developed, tested and broadly utilized. Next, a comprehensive explanatory and descriptive theory of denial needs to be tested. Indeed, an integral part of the deductive research process is developing, testing and refining theory. Finally, denial needs to be measured in relation to other relevant demographic, substance use, treatment and outcome variables.

The overarching goal of all substance abuse treatment discourse is to enlighten our path towards eradicating, preventing or successfully reducing substance use disorders and their accompanying problems. This article makes strides towards achieving that goal. Indeed, this article highlights the theoretical complexity of the construct denial, describes appropriate 
clinical responses to denial based on a particular etiology and organizes and critiques the literature pertaining to etiological theories of denial and corresponding interventions. This article serves as a unique reference tool for counsellors and others who work with substance abusers who exhibit denial. It demonstrates the need for future research that develops and evaluates a comprehensive theory of denial, a universal nominal and operational definition of denial and a standard measurement instrument which captures the complex nature of denial. This will allow empirically generated interventions, which are informed by multiple theories of denial, to be created.

Declaration of interest: The authors report no conflicts of interest. The authors alone are responsible for the content and writing of the article.

\section{References}

Alcoholics Anonymous World Services, Inc. 1956. The big book. New York: Alcoholics Anonymous World Services.

Bean MH. 1981. Denial and the psychological complications of alcoholism. In: Bean M, Zinberg N, editors. Dynamic approaches to the understanding and treatment of alcoholism. New York: Free Press. pp 55-96.

Becker CE. 1978. Medical consequences of alcohol abuse. Postgraduate Medicine 64(6):88-93.

Brehm SS. 1976. The application of social psychology to clinical practice. Washington: Hemisphere Publications Corporation.

Bethesda, MD. 1993. Clinical and pathologic overview of the brain disorders in alcoholics, Research Monograph 22. NIAAA.

DiClemente CC. 1991. Motivational interviewing and the stages of change. In: Miller WR, Rollnick S, editors. Motivational interviewing: Preparing people to change addictive behavior. New York: The Guilford Press.

DiClemente CC. 2003. Addiction and change: How addictions develop and addicted people recover. New York: The Guilford Press.

DiClemente CC, Prochaska JO, Fairhurst SK, Velicer WF, Velasquez MM, Rossi JS. 1991. The process of smoking cessation: An analysis of precontemplation, contemplation, and preparation stages of change. Journal of Consulting and Clinical Psychology 59(2):295-304.

Dolan MJ. 2005. Stages of change. In: Freeman A, editor. Encyclopedia of Cognitive Behavioral Therapy. New York: Springer Science and Business. pp 387-390.

Dorpat TL. 1994. Denial and defense in the therapeutic situation. New York: Jason Aronson Inc.

Doweiko H. 2009. Concepts of chemical dependency. 7th ed. Belmont, CA: Brooks/Cole.

Duffy JD. 1995. The neurology of alcoholic denial: Implications for assessment and treatment. Canadian Journal of Psychiatry 40(5):257-263.

Duffy JD, Campbell JJ. 1994. The regional prefrontal syndromes: A theoretical and clinical overview. The Journal of Neuropsychiatry and Clinical Neurosciences 6(4):379-387.

Edwards G, Hensman C, Peto J. 1973. Drinking in a London suburb. Reinterview of a subsample and assessment of response consistency. Quarterly Journal of Studies on Alcohol 34(4):1244-1254.

Fals-Stewart W, Lucente S, Shanahan T, Brown L. 1995. The relationship of patients' cognitive status and therapists' ratings of psychological distress among psychoactive substance users in long-term residential treatment. Journal of Substance Abuse 7(2):205-222.

Forrest G. 1985. Psychodynamically oriented treatment of alcoholism and substance abuse. In: Bratter T, Forrest G, editors. Alcoholism and substance abuse: Strategies for clinical intervention. New York: Free Press. pp 307-336.

Forrester D, Harwin J. 2006. Parental substance misuse and child care social work: Findings from the first stage of a study of 100 families. Child \& Family Social Work 11(4):325-335.

Freeman A, Dolan M. 2001. Revisiting Prochaska and DiClemente's stages of change theory: An expansion and specification to aid in treatment planning and outcome evaluation. Cognitive Behavioral Practice 8(3):224-234.

Freud S. 1961. The ego and the id and other works. In: Strachey J, editor. The standard edition of the complete psychological works of Sigmund Freud. London: Hogarth Press. 
Grant BF. 1997. Barriers to alcoholism treatment: Reasons for not seeking treatment in a general population sample. Journal of Studies on Alcohol 58(4):365.

Jellinek EM. 1960. The disease concept of alcoholism. New Brunswick, NJ: Hillhouse Press.

Johnson B. 2003. Psychological addiction, physical addiction, addictive character, and addictive personality disorder: A nosology of addictive disorders. Canadian Journal of Psychoanalysis 11(1):135-160.

Johnson J. 2004. Fundamentals of substance abuse. Belmont, CA: Brooks/Cole.

Jones BM. 1971. Verbal and spatial intelligence in short and long term alcoholics. The Journal of Nervous and Mental Disease 153(4):292-297.

Kennard D. 1983. An introduction to therapeutic communities. London: Routledge.

Kerns LL. 1986. Falsifications in the psychiatric history: A differential diagnosis. Psychiatry 49(1):13-17.

Khantzian E. 1999. Treating addiction as a human process. Lanham, MD: Rowman \& Littlefield.

Krestan JA, Bepko C. 1993. On lies, secrets, and silence: The multiple levels of denial in addictive families. In: Imber-Black E, editor. Secrets in families and family therapy. New York: W W Norton \& Co Inc. pp 141-159.

Litowitz BE. 1998. An expanded developmental line for negation: Rejection, refusal, denial. Journal of The American Psychoanalytic Association 46(1):121-148.

Littell JH, Girvin H. 2002. Stages of change: A critique. Behavior Modification 26:223-273.

Lyvers M. 2000. 'Loss of control' in alcoholism and drug addiction: A neuroscientific interpretation. Experimental and Clinical Psychopharmacology 8(2):225-249.

McMahon J, Jones BT. 1992. The change process in alcoholics: Client motivation and denial in the treatment of alcoholism within the context of contemporary nursing. Journal of Advanced Nursing 17(2):173-186.

Miceli M, Castelfranchi C. 1998. Denial and its reasoning. British Journal of Medical Psychology 71:139-152.

Miglioli M, Buchtel HA, Campanini T, De Risio C. 1979. Cerebral hemispheric lateralization of cognitive deficits due to alcoholism. The Journal of Nervous and Mental Disease 167(4):212-217.

Miller F, Barasch A. 1985. The under-reporting of alcohol use: The role of organic mental syndromes. Drug and Alcohol Dependence 15(4):347-351.

Miller TR, Benefield R, Tonigan J. 1993. Enhancing motivation for change in problem drinking: A controlled comparison of two therapist styles. Journal of Consulting and Clinical Psychology 61(3):455-461.

Miller WR, Rollnick S. 2002. Motivational interviewing: Preparing people for change. New York: The Guilford Press.

Miller WR, Sovereign RG. 1989. The check-up: A model for early intervention in addictive behaviors. In: Loberg T, Miller WR, Nathan PE, editors. Addictive behaviors: Prevention and early interventions. Amsterdam: Swets \& Zeitlinger. pp 219-231.

Miller WR, Zweben A, Diclemente C, Rychtarik R. 1992. Motivational enhancement therapy manual: A Clinical research guide for the therapist treating individuals with alcohol abuse and dependence. NIAA: Rockville, MD.

Morse RM, Flavin DK. 1992. The definition of alcoholism. JAMA: Journal of the American Medical Association 268(8):1012.

Moselhy H, Georgiou G, Kahn A. 2001. Frontal lobe changes in alcoholism: A review of the literature. Alcohol and Alcoholism 36(5):357-368.

Nace EP. 1987. The treatment of alcoholism. New York: Brunner/Mazel.

Nixon SJ. 1998. Cognitive efficiency in alcoholics and polysubstance abusers. Alcoholism 22(7):318.

Pal HR, Yadav S, Joy PS, Mehta S, Ray R. 2003. Treatment nonseeking in alcohol users: A community-based study from North India. Journal of Studies on Alcohol 64(5):631-633.

Polcin D, Weisner C. 1999. Factors associated with coercion in entering treatment for alcohol problems. Drug and Alcohol Dependence 54(1):63-68.

Polcin DL. 2003. Rethinking confrontation in alcohol and drug treatment: Consideration of the clinical context. Substance Use \& Misuse 38(2): 165.

Prochaska JO, DiClemente CC. 1983. Stages and processes of self-change of smoking: Toward an integrative model of change. Journal of Consulting and Clinical Psychology 51(3):390-395.

Prochaska JO, DiClemente CC. 1992. The transtheoretical model of change. In: Norcross J, Goldfried M, editors. Handbook of psychotherapy integration. New York: Basic Books.

Rinn W, Desai N, Rosenblatt H, Gastfriend DR. 2002. Addiction denial and cognitive dysfunction: A preliminary investigation. The Journal of Neuropsychiatry and Clinical Neurosciences 14(1):52-57.

Royce JE. 1981. Alcohol problems and alcoholism: A comprehensive survey. New York: Free Press.

SAMHSA. 2006. Results from the 2005 National Survey on Drug Use and Health: National Findings. Available from http://www.oas.samhsa.gov/NSDUH/2k5NSDUH/2k5Results.htm 
Schuckit MA, Daeppen JB, Tipp JE, Hesselbrock M, Bucholz KK. 1998. The clinical course of alcohol-related problems in alcohol dependent and nonalcohol dependent drinking women and men. Journal of Studies on Alcohol 59(5):581-590.

Shaffer HJ, Simoneau G. 2001. Reducing resistance and denial by exercising ambivalence during the treatment of addiction. Journal of Substance Abuse Treatment 20(1):99-105.

Siegal HA, Fisher JH, Rapp RC, Kelliher CW, Wagner JH, O’Brien WF, et al. 1996. Enhancing substance abuse treatment with case management: Its impact on employment. Journal of Substance Abuse Treatment 13(2):93-98.

Siegal HA, Rapp RC, Kelliher CW, Fisher JH, Wagner JH, Cole PA. 1995. The strengths perspective of case management: A promising inpatient substance abuse treatment enhancement. Journal of Psychoactive Drugs 27(1):67-72.

Skinner HA. 1982. The drug abuse screening test. Addictive Behaviors 7(4):363-371.

Stoltzfus K. 2006. An elephant in the sanctuary: Denial and resistance in addicted Christians and their churches. Social Work \& Christianity 33(2):141-163.

Strauss GD. 2002. On addiction denial and cognitive dysfunction in alcoholics. The Journal of Neuropsychiatry and Clinical Neurosciences 14(4):467.

Sullivan EJ, Hale RE. 1987. Nurses' beliefs about the etiology and treatment of alcohol abuse: A national study. Journal of Studies on Alcohol 48(5):456-460.

Taylor A, Kroll B. 2004. Working with parental substance misuse: Dilemmas for practice. British Journal of Social Work 34(8):115-1132.

To SE. 2006. Alcoholism and pathways to recovery: New survey results on views and treatment options. Medscape General Medicine 8(1):2-2.

UN. 2006. The World Drug Report 2006. Available from http://www.unodc.org/unodc/en/data-and-analysis/ WDR-2006.html

van der Walde H, Urgenson FT, Weltz SH, Hanna FJ. 2002. Women and alcoholism: A biopsychosocial perspective and treatment approaches. Journal of Counseling \& Development 80(2): 145 .

Wallace J. 1986. Alcoholism from the inside out: A phenomenological analysis. In: Estes N, Heinemann M, editors. Alcoholism: Development, consequences and interventions. 3rd ed. St. Louis: Mosby. pp 3-14.

Wechsler H, Rohman M. 1982. Future leaders' views on alcohol use and misuse. Journal of Studies on Alcohol 43(11):1084-1096.

Weinstein BA, Raber MJ, Slaght EF. 1999. Reexamining the clinical response to denial in alcoholics. Employee Assistance Quarterly 14(4):45-52.

West R. 2005. Time for a change: Putting the transtheoretical (stages of change) model to rest. Addiction 100:1036-1039.

WHO. 2004. World Health Organization Global Status Report on Alcohol. Available from http://www.who.int/ substance_abuse/publications/alcohol/en/index.html

Wing D. 1995. Transcending alcoholic denial. Image 27:121-126.

Wiseman EJ, Souder E, O'Sullivan P. 1996. Relation of denial of alcohol problems to neurocognitive impairment and depression. Psychiatric Services 47(3):306-308.

Zinn S, Stein R, Swartzwelder H. 2004. Executive functioning early in abstinence from alcohol. Alcoholism, Clinical and Experimental Research 28(9):1338-1346. 